AIAA-98-1962

\title{
EFFECTS OF AGING -TIME REFERENCE ON THE LONG TERM BEHAVIOR OF THE IM7/K3B COMPOSITE
}

\author{
David R. Veazie* \\ Clark Atlanta University \\ Atlanta, GA \\ Thomas S. Gates \\ NASA Langley Research Center \\ Hampton, VA
}

\begin{abstract}
$\underline{\text { ABSTRACT }}$
An analytical study was undertaken to investigate the effects of the time-based shift reference on the long term behavior of the graphite reinforced thermoplastic polyimide composite IM7/K3B at elevated temperature. Creep compliance and the effects of physical aging on the time dependent response was measured for uniaxial loading at several isothermal conditions below the glass transition temperature $\left(T_{g}\right)$. Two matrix dominated loading modes, shear and transverse, were investigated in tension and compression. The momentary sequenced creep/aging curves were collapsed through a horizontal (time) shift using the shortest, middle and longest aging time curve as the reference curve. Linear viscoelasticity was used to characterize the creep/recovery behavior and superposition techniques were used to establish the physical aging related material constants. The use of effective time expressions in a laminated plate model allowed for the prediction of long term creep compliance. The effect of using different reference curves with time/aging-time superposition was most sensitive to the physical aging shift rate at lower test temperatures. Depending on the loading mode, the reference curve used can result in a more accurate long term prediction, especially at lower test temperatures.
\end{abstract}

*Assistant Professor, Member ASME.

$\dagger$ Research Scientist, Member AIAA.

Copyright $\odot 1998$ The American Institute of

Aeronautics and Astronautics Inc. All rights reserved.

\section{INTRODUCTION}

Durability and performance are primary concerns when engineers employ advanced polymer matrix composites (PMCs) for use in modern applications such as those found in aerospace structures. Developing analytical tools to predict long term performance and screen for final materials selection is the impetus for intensive studies at NASA and major industry based airframe developers. The intent of this research is to present the results of a recent analytical study that applies to these concerns.

In polymer-based composites, Bank et al. ${ }^{1}$ showed that the polymeric matrix is often the major constituent that experiences changes in physical and mechanical properties over time due to exposure to elevated temperatures. This change, termed physical aging, can result in changes in the long term composite stiffness, strength and fatigue life. Therefore, in order to develop an understanding of the long term properties of the composite, the properties in directions transverse to the fibers have to be studied. In this research, the matrix dominated transverse and in-plane shear loading modes were investigated in both tension and compression loading directions. Short term data from elevated temperature creep tests were used to determine the effects of physical aging on the long term viscoelastic compliance predictions of IM7/K3B. Several investigators used creep to assess the viscoelastic behavior in PMCs as reviewed by Scott et al. $^{2}$ Results from Gates and Feldman ${ }^{3}$ and Veazie and Gates ${ }^{4}$ showed that the sequence creep testing procedures produced repeatable test data for IM7/K3B laminates loaded in tension and compression. 
This paper extends these investigations by comparing the effects of the aging-time reference used in the time/aging-time superposition technique that provided the parameters required to make long term predictions. Brinson and Gates ${ }^{5}$ determined that the physical aging shift rate was the most critical parameter in calculating the magnitude of agings' effect on the long term performance of PMC's. To establish the background for the analytical methodology, a brief summary is given on linear viscoelasticity and physical aging in composites. The properties of IM7/K3B are given and the experimental equipment and procedures are described. The methods of data reduction are explained including the use of superposition techniques. Direct comparisons are made between the parameters using the shortest, middle and longest aging time curve as the reference. Also, parameters obtained from superposition techniques using horizontal (time) and vertical (compliance) time/aging-time shifts are compared to cases in which only horizontal time/aging-time shifts were used. The long term compliance predictions that result from the use of these parameters, namely the physical aging shift rates, are also compared.

\section{VISCOELASTICITY AND AGING}

An analytical model as provided in Brinson and Gates $^{5}$ was used to predict the long term creep compliance using as input the material properties developed from short term tests. A "long term" test was defined as a test time at least 10 times greater than the time of the "short term" material property tests. For the purposes of this discussion, the model is briefly recounted for tension loading. Apart from the obvious sign differences between tension and compression loading, the tension based model was not modified for analysis of the compression loading. Specific differences concerning tension versus compression behavior can be found in Gates et al. ${ }^{6}$

The time dependent linear creep compliance was modeled with a three parameter expression given by

$$
S(t)=S^{o} e^{(t / \tau)^{\beta}}
$$

where $S^{\circ}, \tau$, and $\beta$ are the initial compliance, retardation time and shape parameter respectively. Short-term creep and recovery tests as shown in Figure 1 provided the material parameters required by the model. Time/aging-time superposition of the

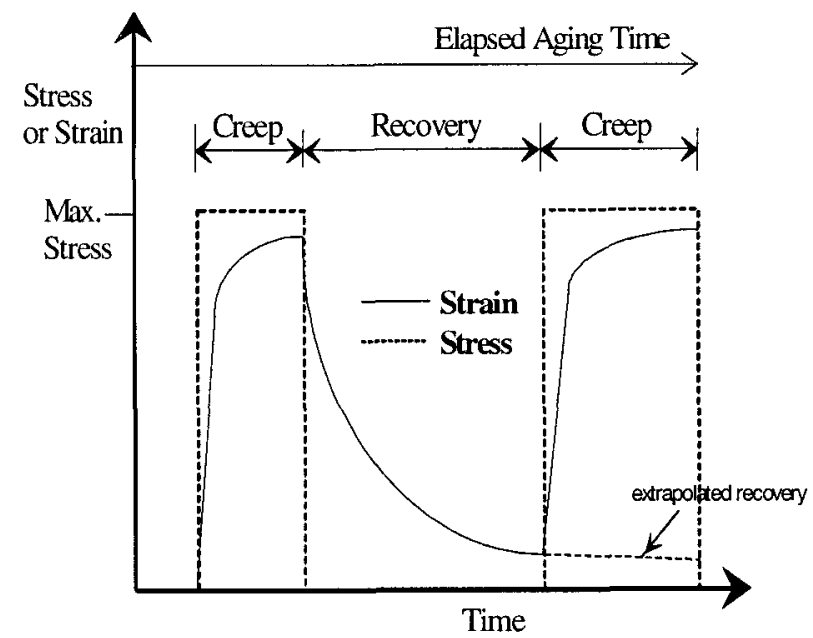

Fig. 1. Sequenced creep compliance test procedures.

short term creep compliance test data provided the means for the sequenced, short term data to be collapsed into a single momentary master curve (MMC) at each test temperature. As demonstrated by Struik ${ }^{7}$ and illustrated in the $\log -\log$ plot of Figure 2, horizontal separation of the sequenced creep compliance curves is due to aging and can be characterized by the aging shift factor $(-\log a)$. This shift factor is simply defined as the horizontal distance required to shift a compliance curve to coincide with a reference compliance curve. A linear fit of all the shift factors versus the logarithmic aging time $\left(\log t_{e}\right)$ for each MMC, (Figure 3 ) gave the aging shift rate $(\mu)$

$$
\mu=\frac{-d \log a}{d \log t_{e}}
$$

where $t_{e}$ is the aging time.

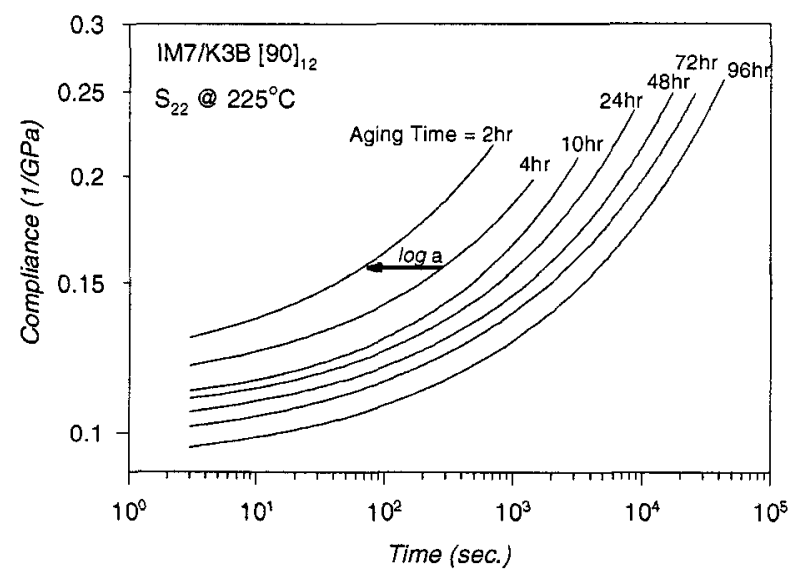

Fig. 2. Typical transverse compression creep compliance momentary curves. 
It was shown by investigators such as Gates and Feldman ${ }^{3}$, Veazie and Gates ${ }^{4}$, Brinson and Gates ${ }^{5}$, and Gates et al. ${ }^{6}$ that the reference compliance curve could be any of the sequenced curves. However, for convenience of data manipulation, each investigator selected the longest (96 hour) compliance curve as the reference during formation of the MMC. In this study, the effects of using the longest compliance curve are compared to using the shortest ( 2 hour) and middle ( 24 hour) compliance curve as the reference curve during formation of the MMC. To facilitate data reporting, however, all MMC parameters were subsequently referenced to the shortest compliance curve.

For a horizontal (time) translation of a compliance curve, only the retardation time parameter needs to be recalculated. Given the aging shift rate and reference curve parameters, the translation from one aging time to another was accomplished through the use of

$$
\tau_{e}=\tau_{\text {ref }}\left(\frac{t_{e}}{t_{\text {eref }}}\right)^{\mu}
$$

where teref is the reference aging time. ${ }^{5}$ Equation 2 implies a linear relation between $\log a$ and $\log t_{e}$. Figure 3 shows this relationship for one of the replicate tests used to establish the MMC's. The shift factors for the data on Figure 3 were found from the curves on Figure 2 and are representative of all the IM7/K3B MMC data.

To facilitate the collapse of the shifted data for the MMC, vertical (compliance) shifts were also utilized by the previous investigators. ${ }^{3-6}$ This use of small

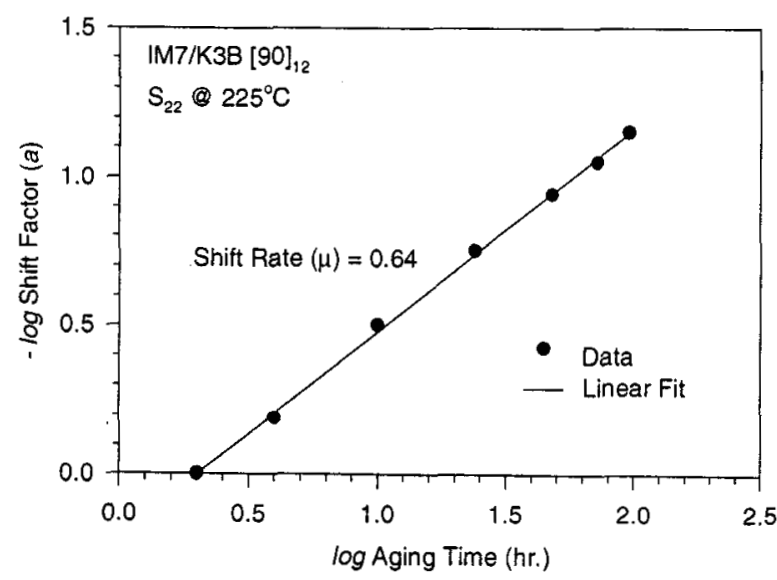

Fig. 3. Typical compression aging shift factor as a function of aging time.

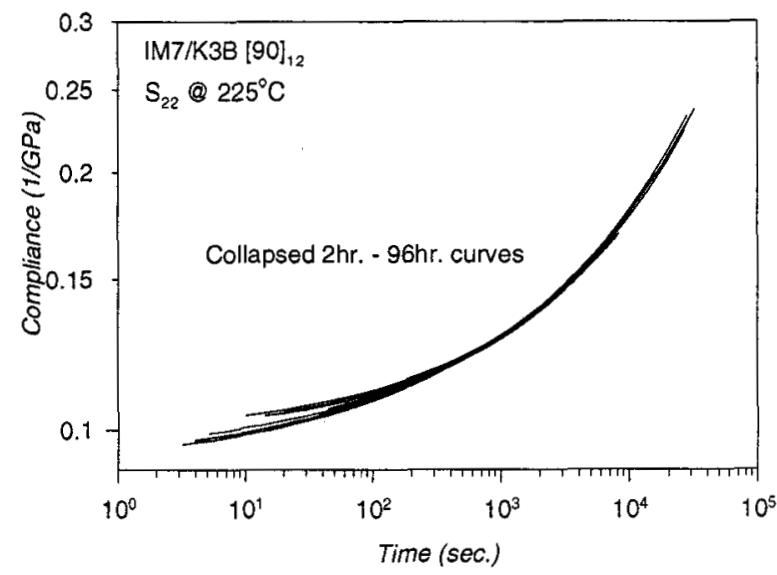

Fig. 4. Typical momentary compression creep compliance during aging.

vertical shifts in reduction of PMC creep compliance/aging data was also reported by Sullivan ${ }^{8}$ and Hastie and Morris. ${ }^{9}$ The vertical shifts for all data sets were small in comparison to the magnitude of the corresponding horizontal (time) shifts. No clear trends existed in these vertical shifts nor did the analysis of vertical shift factors versus aging time lend itself to developing a constant vertical shift rate. However, in this study the use of both horizontal and vertical shifting is compared to cases in which only horizontal shifting is used. Figure 4 illustrates how a typical data set is collapsed through the use of horizontal and vertical shifts.

The analytical model used to make long term creep compliance predictions for PMC's requires a time dependent form of laminated plate theory. For test periods that exceed the time required to collect the short term (momentary) data, the response can be expected to be influenced by the ongoing aging process. Specific formulations of the analytical model, along with the proposed effective time that could be used to replace time can be found in detail in Gates et al. ${ }^{6.7}$ Acceleration of aging in this manner implies that short term tests can be used to determine the equivalent state of degradation experienced in a long term test. In this study, elevated temperature was used as the primary accelerator of the physical aging process. Aging shift rate was found as a function of the test temperature and the predictive model was used to investigate the effects of elevated temperature on creep compliance.

\section{TEST MATERIALS AND EQUIPMENT}

The material system chosen for this study was a continuous carbon fiber reinforced thermoplastic polyimide fabricated by DuPont and designated IM7/K3B. The unaged glass transition temperature $\left(T_{g}\right)$ in the composite as measured by Dynamic Mechanical 
Analyzer (DMA) $G^{\prime \prime}$ peak was $240^{\circ} \mathrm{C}$. Change in the $T_{g}$ from the unaged condition over extended aging times was measured by industrial studies and found to remain within $3^{\circ} \mathrm{C}$ for 10,000 hours of isothermal aging at $180^{\circ} \mathrm{C}^{3}$ For this study, it was therefore assumed that chemical aging of the composite would not occur and the $T_{g}$ would remain constant over the duration of the tests.

Rectangular test specimens similar to those described in ASTM Specification D3039-76 measuring $20.32 \mathrm{~cm}$. by $2.54 \mathrm{~cm}$. were cut from laminated panels. All specimens consisted of 12 or 8 plys where each ply measured approximately 0.0135 $\mathrm{cm}$. thick. To reduce experimental errors at least three replicates were tested at each test temperature. Although all the specimens came from the same material lot, many of the replicate specimens were cut from different panels. Prior to testing, all specimens were dried for at least 24 hours at $110^{\circ} \mathrm{C}$ in a convection oven.

The in-plane transverse $\left(\mathrm{S}_{22}\right)$ and in-plane shear $\left(\mathrm{S}_{66}\right)$ creep compliance data came from unidirectional 12-ply $[90]_{12}$ and angle-ply 8-ply $[ \pm 45]_{2 s}$ specimens, respectively. The use of a $[ \pm 45]_{2 \mathrm{~s}}$ specimen for characterizing shear requires that the shear be induced in the laminate through uniaxial loading. To account for any measured differences due to the applied loading direction, shear behavior was measured from 'tension induced shear' and 'compression induced shear'.

Testing was performed to develop material constants for the analytical model and provide verification of the predictive model. The current study used the long, thin specimens described previously. A uniaxial constant load was applied through a dead-weight cantilever arm system. These tests were performed in convection ovens equipped with digital controllers. For compression testing, a unique apparatus was constructed to allow a tensile creep test frame to be used for application of a compressive load. ${ }^{4}$ The compressive creep apparatus consisted of two rigid frames connected by steel rods running through linear bearings. To ensure stable compression, the specimen was supported from column buckling by lightweight knife edge guides. Column buckling was checked during loading by longitudinally aligned back-to-back strain gages, that would show a lack of parity in strain if simple bending occurred. For recovery, the two inner rigid fixtures of the rigid frames were separated from the specimen by applying a slight force from the creep frame lever arm. These unloading mechanisms provided for virtually unconstrained recovery while allowing the test chamber to remain closed during the entire test sequence. (See Veazie and Gates ${ }^{4}$ for details).

Strain in the specimen gage section was measured with high temperature foil strain gages applied in the center of the specimen. Proper selection of the gage type and adhesive gave coefficient of thermal expansion (CTE) match and stability at elevated temperatures. Thermal apparent strain was corrected for by using the compensating gage technique. ${ }^{10}$ Laminate damage in the form of matrix cracks can alter the strain measurements, therefore after each test sequence the specimens were inspected with an optical microscope for matrix cracks along their exposed edges. These inspections revealed no apparent damage after the sequenced tests.

\section{EXPERIMENTAL PROCEDURES AND DATA REDUCTION}

A well-documented technique that measures the creep compliance as described in Struik $^{7}$ was used to explore the effects of physical aging on the creep properties. This procedure consisted of a sequence of creep and recovery tests using a constant applied load while the specimen isothermally ages. The test temperatures selected for the study were $200^{\circ}, 208^{\circ}, 215^{\circ}$, $220^{\circ}, 225^{\circ}$, and $230^{\circ} \mathrm{C}$. These test temperatures were selected to ensure that measurable aging occurred within the test period. Determination of the stress level necessary to stay within the linear viscoelastic range was made by checking that proportionality conditions and Boltzman's superposition was satisfied. ${ }^{4}$

The duration of each creep segment was $1 / 10$ th the duration of the prior total aging time. The aging times selected for starting each creep segment were 2, 4, 10, 24, 48, 72 and 96 hours. After each creep segment, the specimen was unloaded and allowed to recover until the start of the next creep test. To account for any remaining residual strain due to a lack of complete recovery, the strain measured in the creep segment was corrected by subtracting the extrapolated recovery strain from the prior creep curve as illustrated in Figure 1.

For reduction of the IM7/K3B data, the momentary (short-term) sequenced creep/aging curves were collapsed into MMC's. Each individual MMC was determined using the shortest ( 2 hour), middle ( 24 hour) and longest ( 96 hour) aging time curve as the reference curve. In all cases, a horizontal (time) shift as well as a horizontal and a small (as compared to the horizontal shifts) vertical (compliance) shift was used. An individual MMC was 
found for both transverse and shear loading modes in tension and compression at each individual test temperature. Three curve fit parameters were used to characterize each of the MMC's. The parameters from this fit were termed the momentary master curve parameters for a given temperature. Aging shift rates $(\mu)$ were calculated for all cases using the sets of master curves. These calculated values were averaged and plotted against test temperature in Figures 5-12.

\section{RESULTS AND DISCUSSION}

All of the curves represent the best fit to collapsed data from all replicates ( 3 minimum) used in the test program. The shear mode shifts rates for tension loading shown in Figures 5 and 6 and for compression loading shown in Figures 7 and 8 show little change with respect to the change in the reference curve used. Only with horizontal and vertical shifting does the shifts rates show differences at lower temperatures. At higher temperatures, the shift rates obtained using all three reference curves were virtually identical for each loading type. However in the transverse mode shown in Figures $9-12$, the shift rates varied more than in the shear mode, especially at lower temperatures. The 2 and 24 hour shift rates obtained by horizontal shifting alone showed no clear trend at lower temperatures for both tension and compression loading (See Figures 10 and 12). For horizontal and vertical shifting in compression, the shift rates obtained varied at the lower test temperatures. Similar to the shear mode, all shift references in the transverse mode showed consistency in the shift rates at the higher test temperatures.

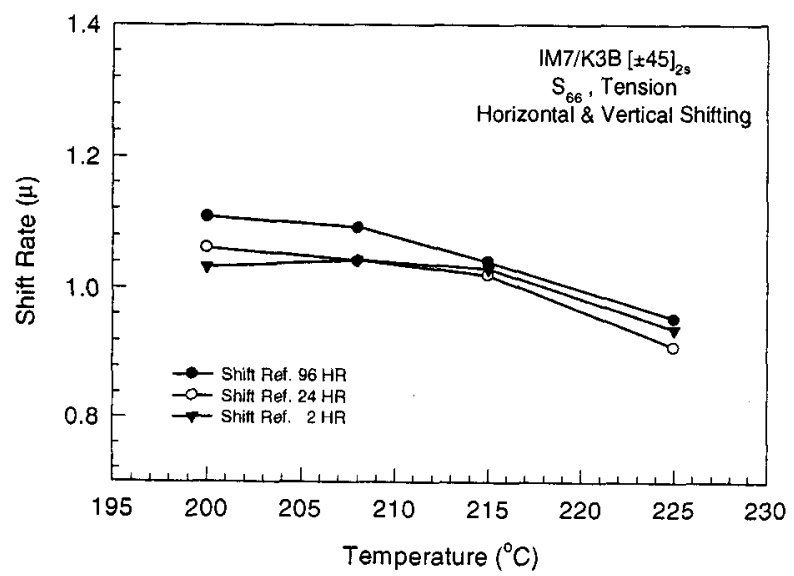

Figure 5. Shear shift rates in tension as a function of temperature using horizontal and vertical shifting.

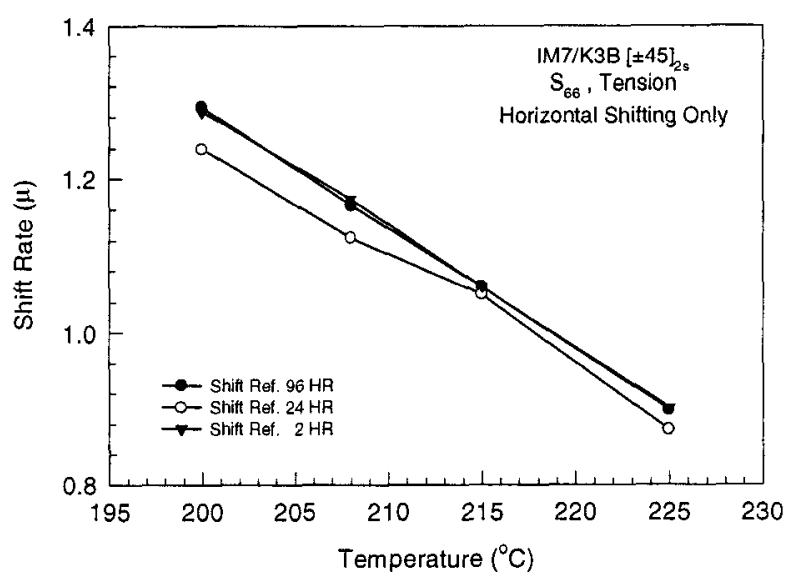

Figure 6. Shear shift rates in tension as a function of temperature using horizontal shifting only.

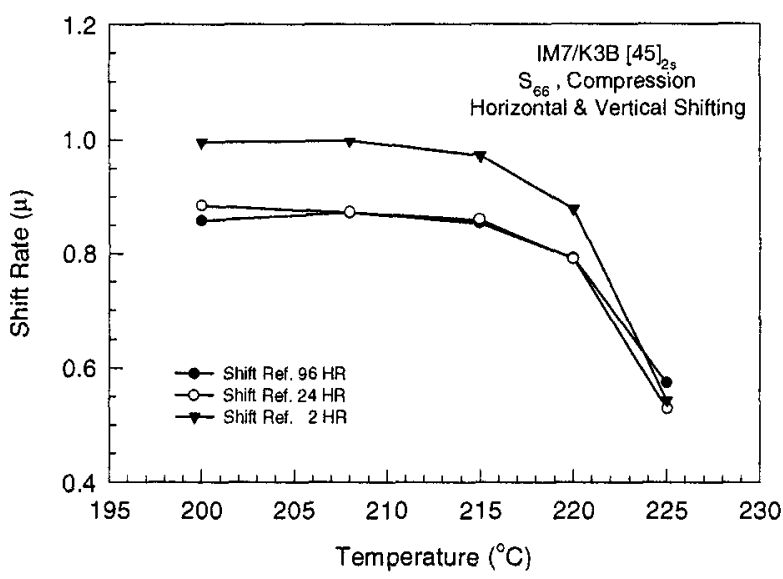

Figure 7. Shear shift rates in compression as a function of temperature using horizontal and vertical shifting.

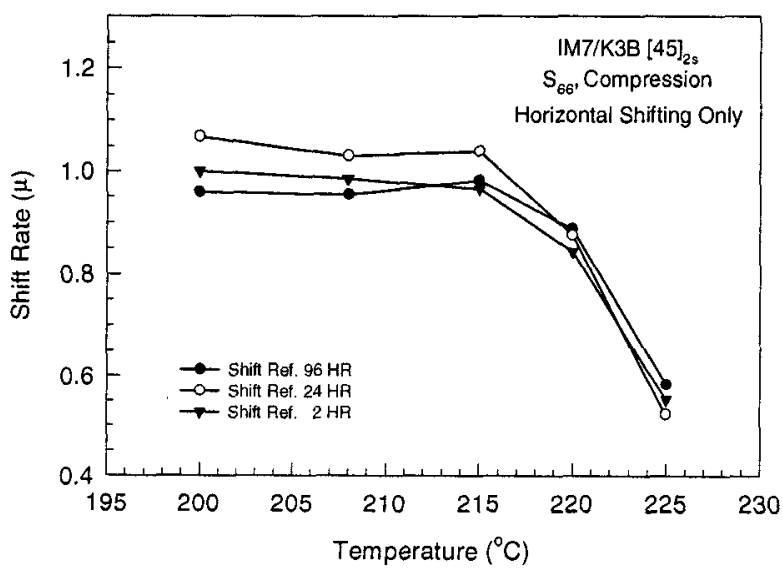

Figure 8. Shear shift rates in compression as a function of temperature using horizontal shifting only. 


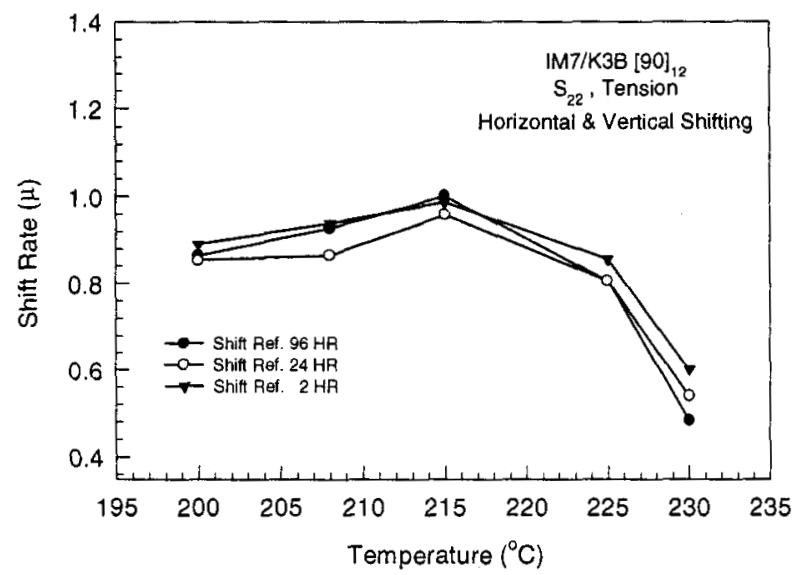

Figure 9. Transverse shift rates in tension as a function of temperature using horizontal and vertical shifting.

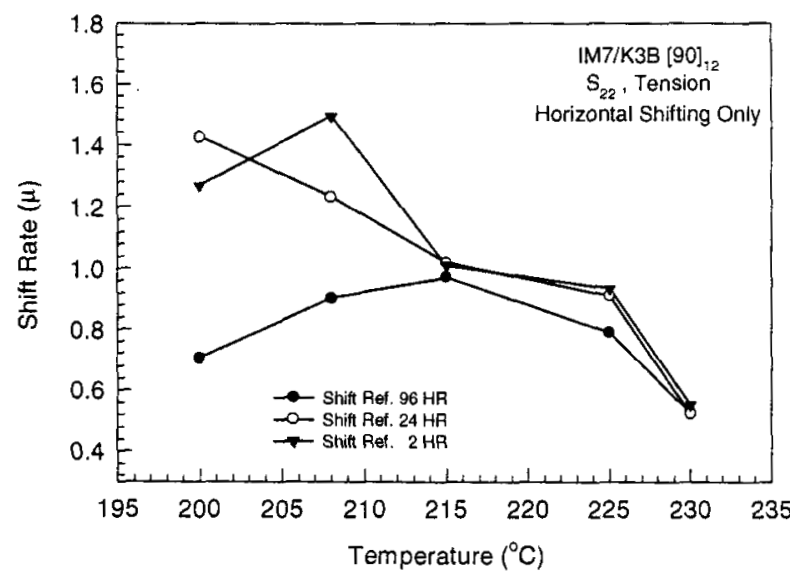

Figure 10. Transverse shift rates in tension as a function of temperature using horizontal shifting only.

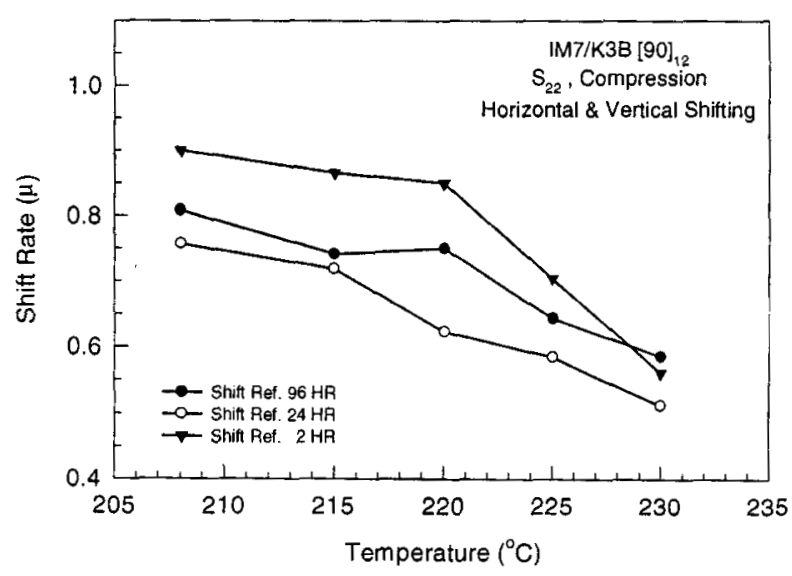

Figure 11. Transverse shift rates in compression as a function of temperature using horizontal and vertical shifting.

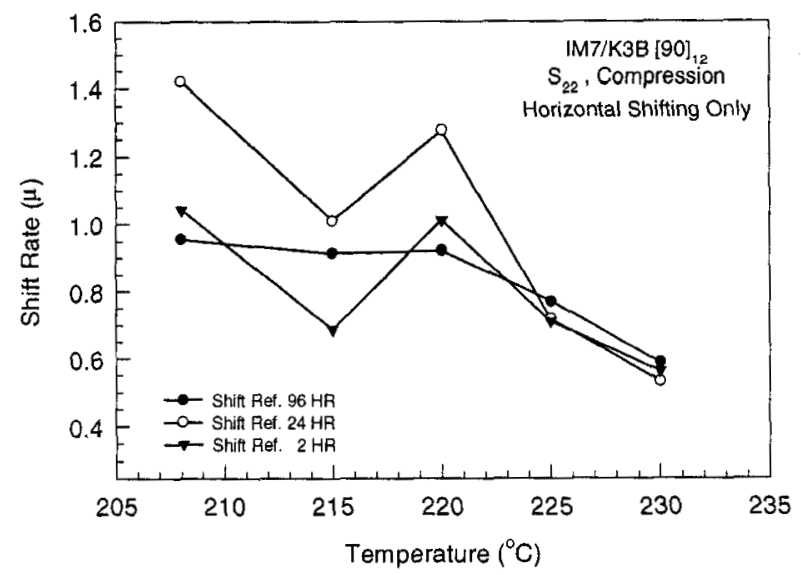

Figure 12. Transverse shift rates in compression as a function of temperature using horizontal shifting only.

Shown in Figures $13-20$ are long term predictions of the creep compliance of $I M 7 / K 3 B$ using the material parameters found from momentary (short term) tests. Plotted with the verification test data was each prediction that was calculated using the shortest ( 2 hour), middle ( 24 hour) and longest (96 hour) aging time curve as the reference curve. Two temperatures, $215^{\circ} \mathrm{C}$ and $225^{\circ} \mathrm{C}$, were selected for all of the long term tests that lasted approximately 11 to 12 times the short term tests. The use of vertical (compliance) shifting in the data reduction over horizontal (time) shifting alone had little effect on the long term predictions.

At the higher test temperature, the use of different reference curves with time/aging-time superposition had little effect on the long term predictions in the shear and transverse mode in both tension and compression. This was the result of the fact that the shift rates at the higher temperatures were virtually identical in all cases. This was also the case at lower test temperatures in tension loading, where only slight differences were observed with the use of different reference curves. However, at the $215^{\circ} \mathrm{C}$ temperature level in compression loading, shifting to the longest ( 96 hour) reference curve resulted in a more accurate prediction in the shear loading mode (See Figures 15 and 16). When transverse loading in compression at $215^{\circ} \mathrm{C}$ was considered, however, only shifting to the shortest ( 2 hour) reference curve resulted in predictions that may not diverge appreciatively from test data for long loading times (See Figures 19 and 20).

\section{CONCLUDING REMARKS}

When a polymeric composites is loaded in compression as studied here, the effect of using different reference curves with time/aging-time superposition is most sensitive to the physical aging shift rate at lower test temperatures. Depending on the loading mode, the reference curve used can result in a more accurate long 


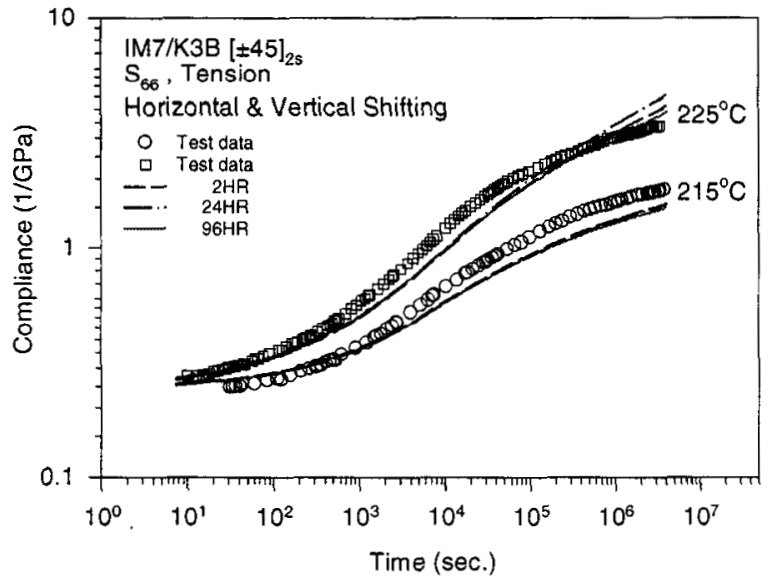

Figure 13. Test versus prediction for long term shear creep tests in tension using horizontal and vertical shifting.

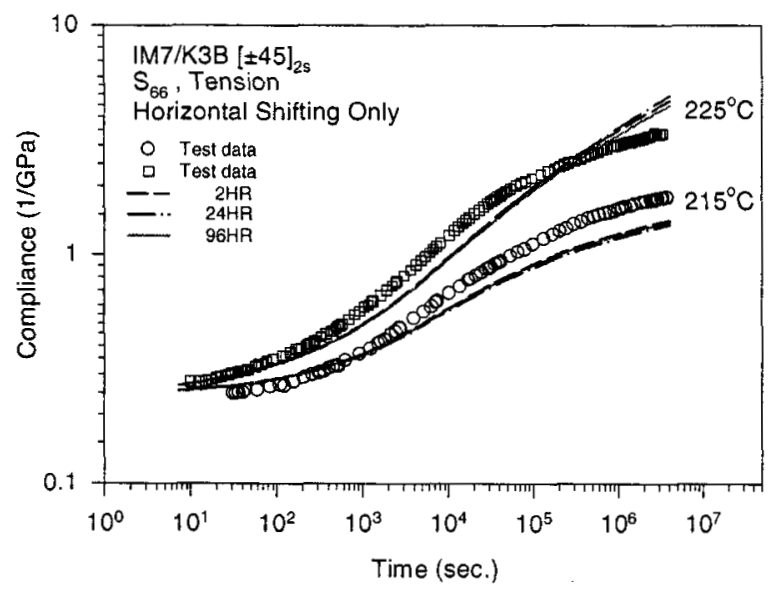

Figure 14. Test versus prediction for long term shear creep tests in tension using horizontal shifting only.

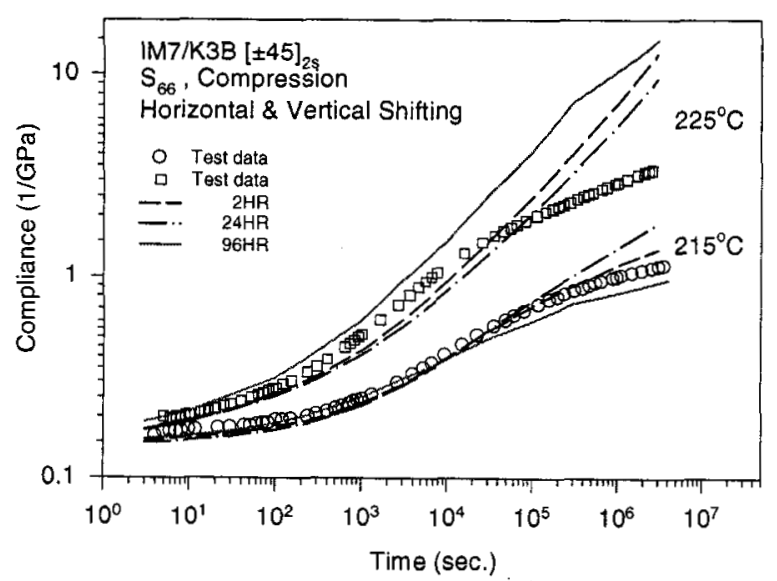

Figure 15. Test versus prediction for long term shear creep tests in compression using horizontal and vertical shifting.

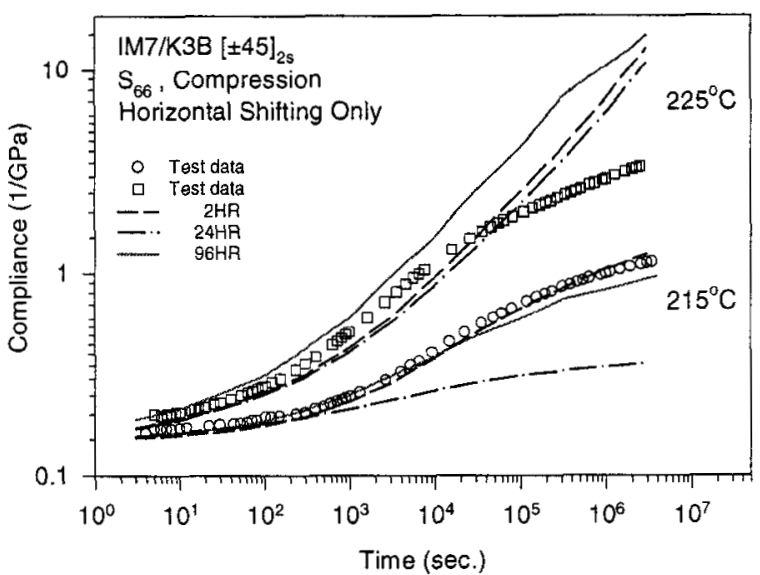

Figure 16. Test versus prediction for long term shear creep tests in compression using horizontal shifting only.

term prediction, especially at lower test temperatures. When longer loading times are considered, certain reference curves used with time/aging-time superposition can result in predictions that do not diverge from test data. In compression loading cases, the influence of the reference curves used should be considered when time/aging-time superposition is used to obtain the critical parameters needed to calculate the magnitude of agings' effect on the long term performance of PMCs.

\section{ACKNOWLEDGMENTS}

The authors gratefully acknowledge the Mechanics of Materials Branch of the NASA Langley Research Center for providing the materials and equipment used in this study. Funding for this work was provided by the NASA Faculty Awards for Research (FAR) under Grant NAG11727 and the NASA Center for High Performance Polymers and Composites (HiPPAC) at Clark Atlanta University under Grant NAGW-2939.

\section{REFERENCES}

1. Bank, L. C., Gentry, T. R. and Barkatt, A., "Accelerated Test Methods to Determine the LongTerm Behavior of FRP Composite Structures: Environmental Effects," Journal of Reinforced Plastics and Composites, Vol. 14, June, 1995, pp. 559-587.

2. Scott, D. W., Lai, J. S. and Zureick, A.-H., "Creep Behavior of Fiber Reinforced Polymeric Composites: A Review of the Technical Literature," Journal of Reinforced Plastics and Composites, Vol. 14, 1995, June, pp. 588-617.

3. Gates, T. S. and Feldman, M., "The Effects of Physical Aging at Elevated Temperatures on the Viscoelastic Creep of IM7/K3B," NASA Langley Research Center, TM- 109114, June, 1994. 


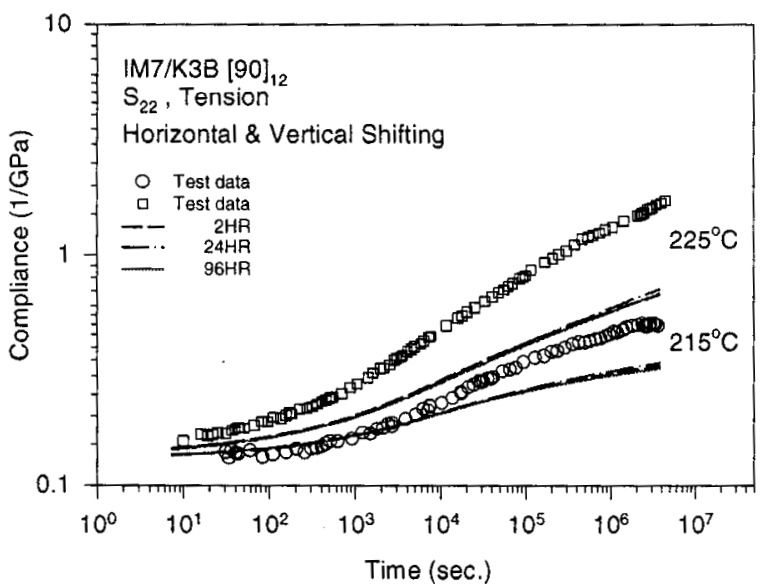

Figure 17. Test versus prediction for long term transverse creep tests in tension using horizontal and vertical shifting.

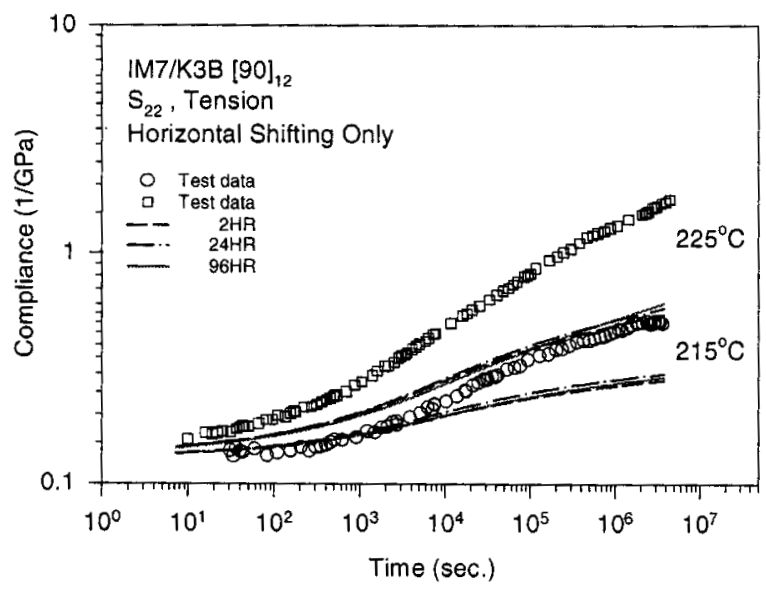

Figure 18. Test versus prediction for long term transverse creep tests in tension using horizontal shifting only.

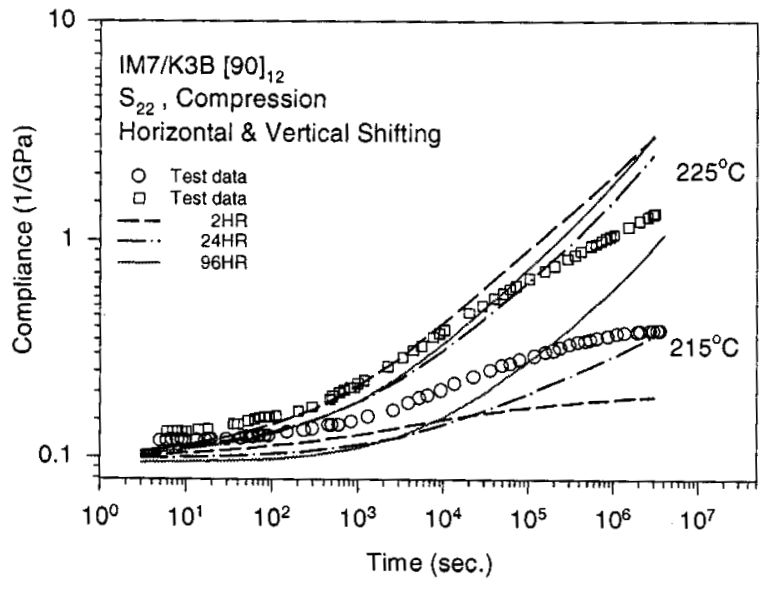

Figure 19. Test versus prediction for long term transverse creep tests in compression using horizontal and vertical shifting.

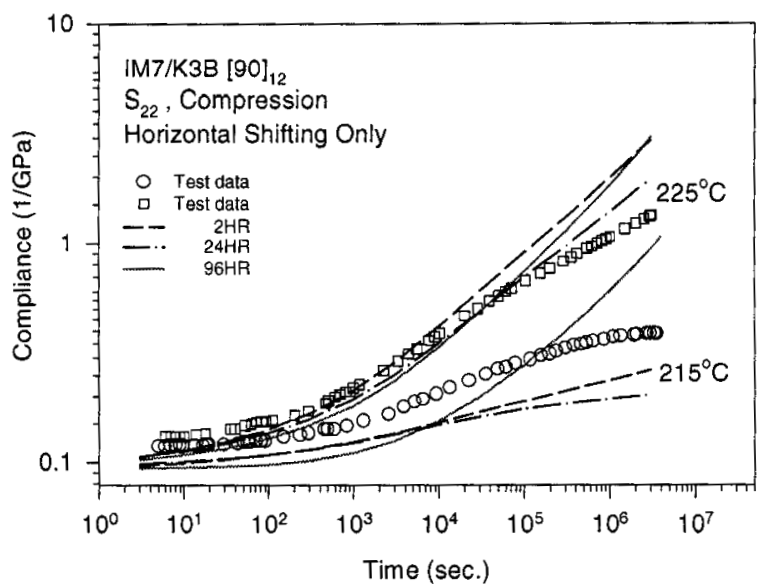

Figure 20. Test versus prediction for long term transverse creep tests in compression using horizontal shifting only.

4. Veazie, D. R. and Gates, T. S., "Compressive Creep of IM7/K3B Composite and the Effects of Physical Aging on Viscoelastic Behavior," Experimental Mechanics, Vol. 37, No. 1, 1997, pp. 62-68.

5. Brinson, L. C. and Gates, T. S., "Effects of Physical Aging on Long Term Creep of Polymers and Polymer Matrix Composites," International Journal of Solids and Structures, Vol. 32, 6/7, 1995, pp. 827846.

6. Gates, T. S., Veazie, D. R., and Brinson, L. C., "A Comparison of Tension and Compression Creep in a Polymeric Composite and the Effects of Physical Aging on Creep," NASA, TM - 110273, August, 1996.

7. Struik, L. C. E., Physical Aging in Amorphous Polymers and Other Materials, Elsevier Scientific Publishing Company, New York, 1978.

8. Sullivan, J. L., "Creep and Physical Aging of Composites," Composites Science and Technology, Vol. 39, 1990, pp. 207-232.

9. Hastie, R. L. and Morris, D. H., "The Effect of Physical Aging on the Creep Response of a Thermoplastic Composite," High Temperature and Environmental Effects in Polymer Matrix Composites, ASTM STP 1174, C. Harris and T. Gates Eds., American Society for Testing and Materials, Philadelphia 1992, pp. 163-185.

10. Murry, W. M., and Miller, W. R., "The Bonded Electrical Resistance Strain Gage," Oxford University Press, New York, 1992. 